\title{
Comunicação sob a ótica de egressos de um currículo integrado em Enfermagem
}

\section{Communication under the optics of graduates of an integrated Nursing curriculum}

\author{
Ana Beatriz Floriano de Souza ${ }^{1}$, Paula Graziela Pedrão Perales ${ }^{2}$, \\ Denise Andrade Pereira Meier ${ }^{3}$
}

\begin{abstract}
Resumo
Objetivo: a presente investigação buscou analisar a percepção de egressos de um currículo integrado em Enfermagem sobre o ensino do tema transversal comunicação. Material e Método: pesquisa qualitativa, descritiva-exploratória, desenvolvida entre egressos do ano de 2013 de uma universidade pública no Sul do Brasil. Os dados foram coletados a partir de um questionário eletrônico com perguntas sobre a abordagem da temática durante a academia. Aplicou-se a técnica de Bardin para análise dos dados. Resultados: o tema tornou-se evidente nas atividades práticas, nas aulas teóricas, nos seminários, especialmente durante o internato, no último ano do curso. Notou-se, também, que os relatos apontaram para a falta de intencionalidade dos docentes na abordagem da comunicação. Conclusão: observou-se a transversalidade do ensino da temática analisada, embora se note limitações nos resultados da análise em virtude do viés de memória dos egressos e do instrumento utilizado para a coleta de dados. Os resultados desvelaram a importância do papel do docente no direcionamento das atividades que exploram os temas transversais de forma clara, sucinta e intencional para garantir a compreensão de todos os acadêmicos sobre os conteúdos estudados e sua importância para o seu futuro profissional.
\end{abstract}

Palavras-chave: Comunicação. Currículo. Educação em enfermagem. Equipe de saúde.

\begin{abstract}
Objective: the present research aimed to analyze the perception of graduates of an integrated curriculum on the teaching of cross-cutting communication theme. Material and Methods: qualitative, descriptive-exploratory research developed among graduates of 2013 from a public university in the South of Brazil. The data were collected from an electronic questionnaire with questions about the thematic approach during the academy. The Bardin technique was used to analyze the data. Results: the theme became evident in the practical activities, in the theoretical classes, in the seminars, especially during the internship, in the last year of the course. It was also noted that the reports pointed to the
\end{abstract}

${ }^{1}$ Graduação em Enfermagem pela Universidade Estadual de Londrina (UEL), Londrina, Paraná, Brasil. E-mail: anabia.enfe@gmail.com

${ }^{2}$ Doutoranda no Programa de Pós-graduação em Enfermagem da Universidade Estadual de Londrina, Londrina, Paraná, Brasil.

${ }^{3}$ Doutorado em Saúde Coletiva pela Universidade Estadual de Londrina, Londrina, Paraná, Brasil. Professora Titular no Departamento de Enfermagem da Universidade Estadual de Londrina, Londrina, Paraná, Brasil. 
lack of intentionality of professors in the approach to communication. Conclusion: it was observed the teaching transversality of the analyzed subject, although limitations were noted in the results of the analysis due to the bias of memory of the egresses and the instrument used for the data collection. The results revealed the importance of the teacher's role in directing the activities that explore the transversal themes in a clear, succinct and intentional way to guarantee the understanding of all the students about the contents studied and their importance for their professional future.

Keywords: Communication. Curriculum. Education in nursing. Health team.

\section{Introdução}

A comunicação é um tema essencial na formação do enfermeiro para capacitá-lo em sua atuação no mercado de trabalho diante das interfaces de sua profissão. A comunicação consiste em veículo de informações, e é à base das relações interpessoais para o desenvolvimento do trabalho em equipe para a enfermagem e para a equipe multiprofissional. $^{(1)}$

A comunicação pode ser conceituada como "o ato que envolve a transmissão e a recepção de mensagens entre o transmissor e o receptor, através da linguagem oral, escrita ou gestual, por meio de sistemas convencionados de signos e símbolos."(2) Pode ser desenvolvida mediante o envolvimento entre dois indivíduos, um sujeito e um coletivo ou coletivos de sujeito. Ainda, relaciona-se a um conjunto de elementos compostos por sujeitos ou objetos, linguagem, discursos, enunciados, interações e vivências, assim como acontecimentos e aspectos sócio-históricos e socioculturais. ${ }^{(3)}$

A resolução do CNE/CES n ${ }^{\circ}$ 3/2001 dispõe sobre as Diretrizes Curriculares Nacionais para os cursos de graduação em Enfermagem (DCN/ENF), e aborda em suas consignas seis competências gerais para a formação dos enfermeiros, entre as quais, inclui-se a comunicação. Segundo as DCN/ ENF, a comunicação é uma competência geral em que o enfermeiro oferece confiabilidade ao receber informações, assim como interage com múltiplos profissionais da saúde e a população assistida. ${ }^{(4)}$ Essa competência encontra-se presente nas DCN dos demais cursos da área da saúde como Fisioterapia, Fonoaudiologia, Terapia Ocupacional, Medicina, Nutrição, Farmácia, Odontologia, Biomedicina e Educação Física. ${ }^{(5-9)}$
No âmbito da saúde a comunicação é primordial para o compartilhamento de mensagens na assistência curativa, pois representa um instrumento que contribui para a recuperação mais rápida do paciente, a qual colabora para a humanização das relações mediante a troca de informações, validação de mensagens e interação com as famílias de pacientes hospitalizados. Favorece, ainda, a relação terapêutica e promoção da saúde por meio do intercâmbio de saberes, de diálogo e de entendimento entre o trabalhador de saúde e o usuário. ${ }^{(10)}$

Ainda, acredita-se que a comunicação propicia a assistência à saúde e promoção do cuidado por ser considerada a base das relações interpessoais. ${ }^{(11)}$ Compreende-se também que a comunicação efetiva coopera para a prevenção de erros, como passagem de casos incompletos, caligrafia ilegível e instruções pouco claras, e duplicidade de procedimentos, entre outras dificuldades nas áreas médica, de enfermagem e das áreas que contemplem a saúde. ${ }^{(12)}$ A comunicação pode ser eletrônica, verbal ou escrita; para que esta seja efetiva, deve ser concisa, propícia e clara, a fim de não ser ambígua, e minimizar os possíveis erros que podem comprometer a qualidade da assistência. ${ }^{(13)}$

Destacam-se diversos desafios nessa área para os profissionais de enfermagem, denominados como barreiras comunicativas. Estas são: a distância física ou corporal, as dificuldades de relacionamento interpessoal entre os integrantes da equipe, a falta de compreensão sobre o trabalho em equipe, a dinâmica de trabalho empregada, a ausência de tempo e a disponibilidade para se dedicarem à comunicação, e as deficiências de conhecimento sobre técnicas de comunicação terapêutica. ${ }^{(14-16)}$ 
Além disso, há barreiras no cuidado em saúde como a linguagem corporal, comunicação ineficaz e o processo educativo não compreendido, que podem afetar diretamente o paciente. ${ }^{(17)}$

A comunicação aberta entre o paciente e a equipe de saúde pode proporcionar respeito e responsabilidade compartilhada. E por meio da linguagem corporal, os sinais transmitidos durante a emissão das mensagens podem sugerir ambiguidade de sentido. $\mathrm{O}$ treinamento educativo deve ser valorizado para promover conhecimento e aumentar a promoção de autocuidado do usuário do serviço de saúde. ${ }^{(17)}$

Os cursos de graduação em Enfermagem ao incluírem a comunicação em sua matriz curricular estarão contribuindo para o desenvolvimento da comunicação efetiva do enfermeiro por direcionar os futuros profissionais na escuta de seus pacientes e na transmissão de informações necessárias. ${ }^{(18)}$ A comunicação na enfermagem torna possível o compartilhamento de ideias, o diálogo com a equipe e a troca de informações. Através dela, o enfermeiro é capaz de exercer seu papel de liderança, gerenciar a equipe e prestar assistência humanizada. ${ }^{(19)}$ Ainda, a cultura, a missão, os objetivos e as estratégias de comunicação adotadas pelas instituições poderão contribuir para o desenvolvimento de processos assistenciais e melhorar a qualidade dos serviços e segurança do paciente. ${ }^{(15)}$ Considerase a comunicação inerente ao trabalho em equipe e transversal a todo processo de enfermagem, ao passo que o ato da comunicação caracteriza-se por acordos e consensos coletivos entre a equipe. ${ }^{(20)}$

Dessa maneira, desde o ano 2000, a Universidade Estadual de Londrina (UEL) implementou o currículo integrado (CI), a partir do uso de metodologias ativas em sua proposta pedagógica. O CI busca inserir ativamente o aluno em seu processo de ensino-aprendizagem, e o professor torna-se um mediador do conhecimento e de experiências. ${ }^{(21)} \mathrm{O}$ curso apresenta a enfermagem enquanto uma prática social, política e historicamente determinada, na qual o enfermeiro é visto como um agente de transformação para atuação na prevenção, na promoção, na reabilitação e na recuperação da saúde. ${ }^{(20)}$ A comunicação compõe dois dos 12 temas transversais do currículo, ou seja, temas que perpassam todos os módulos do curso de graduação articulando-se aos conteúdos específicos. Alguns temas já foram investigados na visão do discente, do docente e dos egressos. Entretanto, outros necessitam ser explorados para aprimoramento dos currículos diante dos desafios do mundo globalizado. ${ }^{(22)}$

Desde a primeira série do curso o currículo integrado propõe o desenvolvimento de habilidades de comunicação verbal como: exposições orais e escritas, pesquisas, elaboração de portfólio e sínteses de temas abordados nos módulos. No segundo ano, são acrescentados no processo de ensino da comunicação os instrumentos básicos de enfermagem e princípios relacionados a essa temática, como: seminários, oficinas e desenvolvimento de pastas temáticas. Na terceira série, aprimora-se o tema com a abordagem de grupos populacionais específicos - gestantes, crianças, adolescentes, idosos, pacientes cirúrgicos e cuidados paliativos. Na última série, os discentes são estimulados ao desenvolvimento de relação de ajuda, educação continuada, pesquisas científicas, comunicação e gestão com trabalhadores nos âmbitos hospitalar e da atenção básica. ${ }^{(22)}$

Por conseguinte, a pergunta que norteou a presente investigação foi: "a proposta pedagógica do CI qualificou os egressos de Enfermagem do ano de 2013 para desenvolver a comunicação em sua prática profissional?". Assim, objetivou-se analisar a percepção de egressos de Enfermagem de um CI sobre o desenvolvimento do tema comunicação durante a graduação.

\section{Material e Método}

Trata-se de um estudo qualitativo, descritivoexploratório, no qual utilizou-se a técnica de entrevista semiestruturada para investigação dos dados. A pesquisa foi desenvolvida entre egressos do curso de graduação em Enfermagem da UEL. Essa instituição de ensino superior foi fundada em 1970, e oferece 53 cursos de graduação e 80 
programas de pós-graduação. Destes, 48 são de mestrado e 32 de doutorado stricto sensu. (21-24) Localiza-se no município de Londrina, Norte do Paraná, que conta com uma população de 506.701 habitantes. ${ }^{(23)} \mathrm{O}$ curso de graduação em Enfermagem iniciou-se em 1972 e, atualmente, apresenta um CI composto por 18 módulos em quatro anos de duração. São ofertadas 60 vagas por ano, em período integral. ${ }^{(21)}$

Foram convidados a participar do estudo egressos do ano de 2013 com vistas a minimizar o viés de memória e a obter resultados de profissionais com certa experiência no mercado de trabalho. Estes foram localizados e contatados por correio eletrônico e por redes sociais. Somente 23 enfermeiros colaboraram efetivamente com esta pesquisa. Os profissionais apresentaram, em média, quatro anos de experiência profissional. As áreas de atuação em enfermagem referidas pelos participantes foram: perioperatória; cuidados intensivos; docência para o ensino técnico e superior; materno-infantil; auditoria; serviços de urgência e emergência e pós-graduação relacionada a mestrado em saúde coletiva e residências em saúde mental, pediatria e obstetrícia.

A coleta de dados deu-se a partir de um instrumento desenvolvido na plataforma Google $\operatorname{Docs}^{\circledR}$, composto por sete questões abertas sobre a abordagem do tema "comunicação" durante a graduação e sua aplicação na prática profissional. Para tanto, questionou-se: "o que você entende por comunicação?; como o termo comunicação foi abordado durante a sua graduação?; em quais módulos o aprendizado sobre o tema comunicação foi mais significativo para você? Por quê?". O período da coleta de dados foi de novembro de 2017 a janeiro de 2018. A anuência do sujeito na participação do estudo foi obtida com sua resposta afirmativa diante da apresentação do projeto de pesquisa, e as questões só foram disponibilizadas àqueles que concordaram.

Os dados foram analisados pela técnica de Bardin. Esta organiza-se em três fases: préanálise, a exploração do material e o tratamento e inferência dos resultados. A primeira prevê a organização dos documentos de análise, assim como a criação de hipóteses, de objetivos e de indicadores que fundamentam a interpretação final. Conseguinte a essa etapa, sucede-se à exploração do material transformando-o em códigos. Eles são classificados como unidades de registro e unidades de contexto que possibilitam a formação de categorias. Posteriormente, realiza-se o tratamento dos resultados com a intenção de criar significado às inferências dos sujeitos participantes e à interpretação deles. ${ }^{(25)}$

Este estudo faz parte de um projeto maior denominado "Análise do currículo integrado do curso de enfermagem da Universidade Estadual de Londrina após quase duas décadas de implantação", e foi aprovado pelo Comitê de Ética em Pesquisa sob CAEE n ${ }^{\circ}$ 65045317.10000.5231. Para garantir o sigilo dos participantes, os relatos foram codificados como E1C a E14C para as questões específicas de comunicação.

\section{Resultados e Discussão}

Foram contatados 23 enfermeiros egressos. Os enfermeiros apresentaram, em média, quatro anos de experiência profissional. As áreas de atuação em enfermagem referidas pelos participantes foram: perioperatória; cuidados intensivos; docência para o ensino técnico e superior; materno-infantil; auditoria; serviços de urgência e emergência; pós-graduação relacionada a mestrado em saúde coletiva e residências em saúde mental, pediatria e obstetrícia.

As percepções dos egressos sobre o desenvolvimento do tema transversal comunicação no decorrer de sua formação resultaram na construção da categoria Comunicação; por conseguinte, elaborou-se seis subcategorias de análise: 1. As formas de comunicação; 2. A abordagem transversal da comunicação no curso; 3. A abordagem superficial do tema; 4. A importância da comunicação na prática profissional; 5. A importância do internato no desenvolvimento da comunicação; e 6. A comunicação como competência essencial. 


\section{Comunicação}

Os resultados que configuram essa categoria dizem respeito ao ensino do tema em um CI e a relevância da temática para prática profissional. Os egressos conceituaram a comunicação como um veículo de informações capaz de transmitir mensagens. Como mostram os discursos a seguir:

Necessita de um emissor e um receptor. (E1C).

É a transmissão de informações ou a entrega de mensagens a outra pessoa. (E8C).

Relação entre uma fonte e um receptor. (E9C).

É $o$ ato de transmitir e receber mensagens por meio de uma troca de informações. (E10C).

Para que a comunicação ocorra os egressos evidenciaram a necessidade da presença de apenas dois componentes do processo de comunicação. Esse consiste em transmitir e em receber mensagens por intermédio de signos, símbolos ou sinais, o que garante a dinamização da comunicação em curto ou longo prazo. A comunicação é composta por um emissor e um receptor, os quais transmitem mensagens por um canal e obtêm uma resposta. De maneira geral, espera-se que esse processo seja constituído pela mensagem, emissor, receptor, código e o decodificador. ${ }^{(26)}$ A partir desse conceito, notase que os egressos compreenderam parcialmente como se efetua a comunicação em sua totalidade de componentes.

De acordo com os pareceres CNE/CES $n^{\circ} 1.210 / 2001 ; n^{\circ} 1.300 / 2001 ; n^{\circ} 1.133 / 2001$; $n^{\circ} 104 / 2002 ; n^{\circ} 138 / 2002$, as DCN, respectivamente, dos cursos de graduação em Fisioterapia, Fonoaudiologia, Terapia Ocupacional, Enfermagem, Medicina, Nutrição, Farmácia, Odontologia, Biomedicina e Educação Física dispõem sobre as competências gerais que o profissional de saúde deve ter, dentre estas a comunicação. Esta deve ser acessível e preservar a confidencialidade das informações com os demais profissionais de saúde e o público em geral. Os pareceres conferem que a comunicação engloba a comunicação verbal, não verbal e habilidades de escrita e leitura, assim também como o conhecimento de ao menos uma língua estrangeira e tecnologias de comunicação e informação. ${ }^{(5-9)}$

\section{As formas de comunicação}

Ainda em relação ao conceito, os participantes trouxeram os tipos de comunicação: verbal e não verbal.

Por meio de gestos, palavras proferidas $e$ escritas, sons e a postura corporal. (E1C).

[...] pode ser dada por meio da fala, de forma manuscrita ou vídeos. (E8C).

[...] linguagem verbal e não verbal. (E13C).

Pode ser escrita, falada, por meio de expressões faciais, gestos ou meio eletrônico. (E14C).

A comunicação pode ser classificada como verbal, mediante o uso de palavras expressas pela fala ou de maneira escrita. Já a não verbal desenvolve-se por meio de gestos, de silêncio, de expressões faciais e de postura corporal. Como exemplo da forma não verbal, observamse as respostas fisiológicas dos pacientes a partir da verificação dos sinais vitais e das expressões decorrentes do processo fisiológico de saúde. Nesse sentido, considera-se, ainda, a comunicação interpessoal, a qual alia os tipos verbal, não verbal e fisiológico ao compreender a realidade em que os sujeitos estão inseridos, os interlocutores (emissor ou receptor), a decodificação e os meios ou veículos utilizados para transmitir as informações. ${ }^{(27)}$

Observou-se a partir dos depoimentos, que os enfermeiros possuem entendimento dos tipos de comunicação ao descreverem as formas verbal e não verbal. No entanto, entende-se que os egressos não pontuaram sobre a comunicação interpessoal que permeia o processo de transmissão de mensagens. 
2. A abordagem transversal da comunicação no curso

As estratégias de ensino de comunicação relatadas pelos egressos relacionaram-se à pesquisa e à participação em atividades práticas. Ressalta-se que, novamente, foram registradas pelos egressos as experiências com temas inerentes ao cenário ético-legal, no sentido de serem assuntos delicados.

Tivemos aula e discutimos sobre o assunto por meio da pesquisa de artigos que tratassem do tema. (E6C).

Estive presente em consultas nas quais eram divulgados os resultados positivos de HIV. (E11C).

[...] foi abordado constantemente durante toda a graduação [...], aprendemos a importância da verbalização com paciente e demais profissionais como enfermeiros, técnicos, médicos etc. (E13C).

Em contraponto aos resultados obtidos com o ensino pontual da comunicação na presente pesquisa, os autores Carvalho, Vitor, Cogo, Santos e Ferreira Júnior ${ }^{(27)}$ apontaram acerca da aprendizagem significativa, em que o processo de ensino na graduação em Enfermagem deve ser contínuo, dinâmico, dialógico, com uso de estratégias de ensino adequadas à realidade dos alunos, a fim de que o conteúdo gere significado a partir do diálogo e da ética discursiva para a condução a um raciocínio clínico que viabilize uma assistência de qualidade. Reforçam, ainda, que o diálogo é um espaço na formação pedagógica que auxilia na promoção da comunicação aos estudantes, bem como à estimulação do pensamento crítico que direciona a reflexão sobre as atitudes dos estudantes em seus locais de prática.

Uma revisão de literatura acerca do ensino da comunicação em saúde apontou que, de maneira direta ou indireta, estudantes de nível superior de ensino em saúde tiveram acesso ao tema e referiram a importância do ensino transversal e da abordagem das habilidades ou competências de comunicação nas disciplinas ou módulos do currículo, assim como o uso de metodologias ou atividades de ensino-aprendizagem que fomentem a discussão na formação dos discentes. ${ }^{(22)}$

A transversalidade do tema comunicação no curso em estudo foi denotada por egressos que expressaram sua abordagem desde o início da graduação, tanto na teoria quanto na prática, a partir de sucessivas aproximações. Segue discurso demonstrando esse resultado:

Na teoria e na prática tivemos sucessivas aproximações. Desde os primeiros estágios em grupo, ao acompanhar professores. (E8C).

Espera-se que a abordagem transversal do tema perpasse todos os módulos e séries da graduação do CI. Para tanto, desde a primeira série do curso, o CI propõe o desenvolvimento de habilidades de comunicação verbal, como: exposições orais e escritas, pesquisas, elaboração de portfólio e sínteses de temas abordados nos módulos. No segundo ano, são acrescentados no processo de ensino da comunicação os instrumentos básicos de enfermagem e os princípios relacionados a essa temática, como seminários, oficinas e desenvolvimento de pastas temáticas. Na terceira série, aprimora-se o tema com a abordagem de grupos populacionais específicos (gestantes, crianças, adolescentes, idosos, pacientes cirúrgicos e cuidados paliativos). $\mathrm{Na}$ última série, os discentes são estimulados ao desenvolvimento de relação de ajuda, educação continuada, pesquisas científicas, comunicação e gestão com trabalhadores nos âmbitos hospitalar e da atenção básica. ${ }^{(22)}$

\section{A abordagem superficial do tema}

Contudo, alguns egressos descreveram como o ensino teórico foi explorado de modo superficial, em virtude de a comunicação ter sido explorada na prática, a partir do envolvimento com outros profissionais. 
Aprendemos superficialmente sobre a importância. (E1C).

Não foi abordado como conteúdo, e sim na prática, com outros profissionais. (E5C).

Foi abordado sucintamente e de forma breve. (E9C).

Dessa forma, observou-se a importância da exposição da temática de forma clara e intencional para gerar significado tanto em sua vida acadêmica quanto em suas práticas profissionais. $\mathrm{O}$ ensino da comunicação nos cursos de graduação em saúde são fundamentais para a formação e a prática profissional. Por meio dessa competência geral é possível aproximar estratégias, habilidades e atitudes para prestar atendimento ao usuário do serviço de saúde, sem desconsiderar o processo ensino-aprendizagem relacionado ao contexto em que o discente ou profissional esteja inserido. ${ }^{(28)}$

\section{A importância da comunicação na prática profissional}

Ademais, os egressos consideraram a comunicação enquanto uma competência essencial para o trabalho do enfermeiro na articulação entre os membros da equipe e de todas as ações do processo de enfermagem, conforme os relatos a seguir:

Aprendemos que, sem a comunicação, não há ação e, consequentemente, resposta. (E2C).

A comunicação é essencial para a enfermagem e sempre foi abordada dessa maneira. (E4C).

[...] elemento essencial para o trabalho em equipe. (E7C).

É uma ferramenta importante e necessita de um processo de desenvolvimento. (E8C).

Embora não tenha sido registrada nos relatos dos egressos como sucede a comunicação escrita nas formas de anotação e evolução de enfermagem, esta é uma importante competência que permeia e respalda juridicamente as ações da prática do enfermeiro. $^{(29)}$
Dessa maneira, a abordagem do tema durante a academia tem como propósito conceder experiências ao discente, a fim de que este compreenda o valor e o sentido na prática profissional, pois o enfermeiro é responsável por informar e avaliar a saúde do paciente de forma efetiva e com acolhimento, considerando as necessidades individuais e coletivas. ${ }^{(30)}$

Sendo assim, o desenvolvimento desta temática poderá auxiliar os futuros enfermeiros na liderança da equipe, a qual requer a transferência de informações referentes aos cuidados com os pacientes de forma clara, o estreitamento de laços entre os profissionais e a compreensão das necessidades dos trabalhadores e usuários dos serviços de saúde. A comunicação tem ligação direta com a competência de liderança, também mencionada nas DCN/ENF. Ou seja, o ato de se comunicar facilita o processo de liderar/gerenciar equipes, realizar mudanças no ambiente de trabalho, assistência em saúde no processo do cuidado, solucionar conflitos e contribuir para tomada de decisões. ${ }^{(16)}$

\section{A importância do internato no desenvolvimento da comunicação}

Outro aspecto abordado faz referência à importância da prática para o desenvolvimento da competência comunicação na formação do enfermeiro em um CI. Esta foi evidenciada mediante a prática de estágios para construção do conhecimento da temática. Neste currículo, o estágio semi-supervisionado ocorre na quarta série do curso no módulo Internato de Enfermagem. A seguir transcrevem-se trechos que retratam esse resultado:

Durante o internato, ao estarmos sozinhos no campo de prática, essa habilidade é muito mais aperfeiçoada. (E8C).

Essa unidade possui suas particularidades, assim, aprendi a me portar e a conversar sobre assuntos que são considerados 'tabus'. No internato, tive a primeira experiência ao dar a notícia da morte a uma família. Sem dúvidas, 
a comunicação precisou ser bem efetiva, a fim de não causar danos psicológicos aos entes queridos. (E9C).

Durante o internato, o tema comunicação foi mais significativo para mim, pois estávamos atuando em equipe juntamente com enfermeiros. (E14C).

Infere-se que a prática de estágio foi mais significativa para os depoentes, em virtude de eles terem exercido a função de enfermeiros e de representarem papel fundamental na equipe, bem como na vida dos pacientes, como relatou a fala do estudante E9C ao ser o comunicador de assuntos considerados delicados na condição de estudante em que se encontrava. $\mathrm{O}$ internato consiste em uma experiência pré-profissional no último semestre do curso de graduação, e permite aos alunos um preparo para o mercado de trabalho, tal como possui foco para a gerência da assistência de enfermagem na área hospitalar e de atenção básica e tem como intenção preparar profissionais para as áreas da gestão e da pesquisa. ${ }^{(30)}$

\section{Comunicação como competência essencial}

Nos discursos, ficou evidente a importância da comunicação para o desenvolvimento do trabalho em equipe, como descrito a seguir:

A comunicação, em todas as suas formas, é essencial no trabalho em equipe, de modo que um não subsiste sem o outro. (E1C).

A prática em comunicação só é desenvolvida estabelecendo vínculos; assim, o trabalho em equipe parte do mesmo pressuposto. (E9C).

Sempre que possivel elogio e parabenizo a equipe pelo bom trabalho e oriento quando julgo necessário. Sempre da melhor maneira possivel, buscando compreender o tempo e as necessidades de cada colaborador, pois as pessoas são diferentes e devemos ouvi-las $e$ compreendê-las para nos comunicarmos bem e desenvolver um excelente trabalho em equipe. (E14C).
Observou-se que os egressos não apresentaram relatos sobre a comunicação escrita, a despeito da legislação. Tal forma de comunicação é essencial, pois oficializa a assistência do enfermeiro.

Nesse sentido, acredita-se que para oferecer uma assistência de qualidade integral ao paciente, o cuidado de enfermagem demanda do profissional um olhar holístico, escuta, humanização, ética, liderança, gerenciamento de recursos humanos e materiais, competências pedagógicas, relacionamento interpessoal, trabalho em equipe e o domínio da comunicação como ferramenta para obter vínculo com os pacientes e com os integrantes da equipe. ${ }^{(1)}$

\section{Conclusão}

O tema comunicação mostrou-se essencial e intrínseco ao processo de trabalho em enfermagem. A comunicação pode ser conceituada como uma competência utilizada tanto na transmissão de informações quanto na articulação do trabalho em equipe. Logo, optou-se pela investigação dessa temática em um só momento na presente pesquisa. Foram consideradas limitações deste estudo em seus resultados em decorrência da criação do instrumento da coleta de dados viabilizado pela plataforma Google Docs ${ }^{\circledR}$. Não obstante a isso, a escolha se deu em razão da dificuldade de acesso pessoal aos egressos do currículo integrado (CI) do ano de 2013.

Além disso, destacou-se a importância das atividades práticas para a consolidação do processo ensino-aprendizagem mediante a inserção dos egressos nos serviços de saúde e equipes de trabalho. Os achados conduzem à reflexão sobre a importância do papel do docente no direcionamento das atividades que exploram os temas transversais. $\mathrm{O}$ docente, em sua atuação no CI, poderá nortear o raciocínio dos discentes para o alcance dos objetivos propostos em cada módulo de forma clara, sucinta e intencional. Dessa forma, ao abordar o tema comunicação, deverá dispor de estratégias que garantam a compreensão de todos sobre os conteúdos estudados. 
Por fim, entende-se a importância de desenvolver a temática durante a formação do enfermeiro utilizando metodologias distintas, a fim de provocar no futuro profissional a aprendizagem significativa desde o início da graduação, visto que ele é responsável pela liderança da equipe de enfermagem e das equipes circunscritas ao processo de trabalho em saúde. ${ }^{(19)}$

\section{Referências}

1 Leal LA, Camelo SHH, Soares MI, Santos FC, Correa R, Chaves LDP. Competências profissionais para enfermeiros: a visão de discentes de graduação em enfermagem. Rev Baiana Enferm. [Internet]. 2016 set. [citado 2018 jul 25];30(3). Disponível em: https:// portalseer.ufba.br/index.php/enfermagem/ article/view/16380

2 Michaelis Moderno Dicionário da Língua Portuguesa. São Paulo: Melhoramentos; 2018. Comunicação [Internet]. [citado 2018 jul 5]. Disponível em: http://michaelis.uol.com.br/ moderno-portugues/busca/portugues-brasileiro/ comunica $\% \mathrm{C} 3 \% \mathrm{~A} 7 \% \mathrm{C} 3 \% \mathrm{~A} 3 \mathrm{o} /$

3 Pereira RL. Conceito de comunicação. Revista e-Com [Internet]. 2013. [citado 2018 ago 19];6(2):1-17. Disponível em: http:// revistas.unibh.br/index.php/ecom/article/ view/1059/642

4 Brasil. Ministério da Educação. Resolução CNE/CES $n^{\circ}$. 3, de 7/11/2001. Institui Diretrizes curriculares nacionais do curso de graduação em enfermagem. Diário Oficial da União [Internet]. 2001 nov; [citado 2018 ago 22]; Seção 1. Disponível em: http://www.cofen. gov.br/resoluo-cne-ces-n-3-de-7-de-novembrode-2001-diretrizes-nacionais-curso-graduaaoenfermagem 6933.html

5 Brasil. Ministério da Educação. Resolução CNE/CES no. 1.300, de 06/11/2001. Diretrizes Curriculares Nacionais dos Cursos de Graduação em Farmácia e Odontologia. Diário Oficial da União [Internet]. $2001 \mathrm{dez}$ 7; [citado 2020 maio 19]; Seção 1. Disponível em: http://portal.mec. gov.br/cne/arquivos/pdf/CES1300.pdf
6 Brasil. Ministério da Educação. Resolução CNE/CES nº. 1.133, de 07/08/2001. Diretrizes Curriculares Nacionais dos Cursos de Graduação em Enfermagem, Medicina e Nutrição. Diário Oficial da União [Internet]. 2001 out 3; [citado 2020 maio 19]; Seção 1. Disponível em: http://portal.mec.gov.br/ dmdocuments/ces1133.pdf

7 Brasil. Ministério da Educação. Resolução CNE/CES n ${ }^{\circ}$. 0.104, de 13/03/2002. Diretrizes Curriculares Nacionais do Curso de Graduação em Biomedicina. Diário Oficial da União [Internet]. 2002 abr. 11; [citado 2020 maio 19]; Seção 1. Disponível em: http://portal.mec.gov. br/cne/arquivos/pdf/CES0104.pdf

8 Brasil. Ministério da Educação. Resolução CNE/CES no. 0.138, de 03/04/2002. Diretrizes Curriculares Nacionais do Curso de Graduação em Educação Física. Diário Oficial da União [Internet]. 2002 abr. 26; [citado 2020 maio 19]; Seção 1. Disponível em: http://portal.mec.gov. br/cne/arquivos/pdf/2002/pces138_02.pdf

9 Brasil. Ministério da Educação. Resolução CNE/CES nº. 1.210, de 12/09/2001. Diretrizes Curriculares Nacionais dos Cursos de Graduação em Fisioterapia, Fonoaudiologia e Terapia Ocupacional. Diário Oficial da União [Internet]. $2001 \mathrm{dez} .10$; [citado 2020 maio 19]; Seção 1. Disponível em: http://portal.mec. gov.br/cne/arquivos/pdf/pces1210_01.pdf

10 Martins PF, Perroca MG. Necessidades de cuidados: o olhar do paciente e da equipe de enfermagem. Rev Bras Enferm [Internet]. 2017. [citado 2018 ago. 18]; 70(5):1080-6. Disponível em: http://www.scielo.br/scielo. php?script $=$ sci arttext\&pid $=$ S0034716720170 00501026\&lang $=\mathrm{pt}$

11 Brasil. Ministério da Saúde. Metas Internacionais de Segurança do Paciente [Internet]. 2013. [citado 2018 ago. 28]. Disponível em: https://proqualis.net/folder/folder-das-6metas-internacionais-de-seguran $\% \mathrm{C} 3 \% \mathrm{~A} 7 \mathrm{a}-$ do-paciente

12 Organização Mundial da Saúde. Oficina de segurança do paciente: aprendendo com os erros. Proqualis: Workshop sobre Segurança do Paciente Aprendendo com Erro [Internet]. 
2008 [citado 2020 maio 19]. Disponível em: https://proqualis.net/livro/oficina-deseguran $\% \mathrm{C} 3 \% \mathrm{~A} 7 \mathrm{a}$-do-paciente-aprendendocom-os-erros

13 Oliveira JSB, Suto CSS, Silva RS. Tecnologias leves como práticas de enfermagem na atenção básica. Rev Saúde.Com [Internet]. 2016. [citado 2018 jul 28]; 12(3):613-21. Disponível em: http://periodicos2.uesb.br/index.php/rsc/ article/view/425/344

14 Nogueira JWS, Rodrigues MCS. Comunicação efetiva no trabalho em equipe em saúde: desafio para a segurança do paciente. Cogitare Enferm [Internet]. 2015 jul. [citado 2018 jul 5]; 20(3):636-40. Disponível em: https://revistas. ufpr.br/cogitare/article/view/40016/26245

15 McKenna L, Brown T, Boyle M, Williams B, Palermo C, Molloy E. Listening and communication styles in nursing students. J Nurs Educ Pract [Internet]. 2014. [citado 2018 jul 5]; 14(11):50-8. Disponível em: http:// www.sciedu.ca/journal/index.php/jnep/article/ view/4741/3266

16 Vasconcelos RMA, Caldana G, Lima EC, Silva LDM, Bernardes A, Gabriel CS. A comunicação no relacionamento entre líderes e liderados no contexto da enfermagem. Rev Enferm UFPE On Line [Internet]. 2017. [citado 2018 jul. 25]; 11(Supl. 11): 4767-77. Disponível em: https://periodicos. ufpe.br/revistas/revistaenfermagem/article/ view/231220/25237

17 Oliveira AM, Soares E. A comunicação como ferramenta educativa no préoperatório mediato de transplante renal. Rev Pesqui Cuid Fundam (Online) [Internet]. 2018 jul. [citado 2018 ago. 26]; 10(3):753-7. Disponível em: http://www. seer.unirio.br/index.php/cuidadofundamental/ article/view/6190/pdf

18 Souza GC, Peduzzi M, Silva JAM, Carvalho BG. Trabalho em equipe de enfermagem: circunscrito à profissão ou colaboração interprofissional? Rev Esc Enferm USP [Internet]. 2016. [citado 2018 jul. 7]; 50(4):6429. Disponível em: http://www.scielo.br/scielo. php?pid=S008062342016000400642\&script $=$ sci_abstract\&tlng=pt
19 Costa TV, Guariente MHDM. Enfermeiros egressos do currículo integrado: inserção e atuação profissional. Rev Enferm UFPE On Line [Internet]. 2017 jan. [citado 2018 jul. 6]; 11(1): 77-85. Disponível em: https://periodicos. ufpe.br/revistas/revistaenfermagem/article/ view/11880/14337

20 Universidade Estadual de Londrina. Curso de Enfermagem UEL. Projeto pedagógico. [Internet]. 2018. [citado 2018 set. 17]. Disponível em: http://www.uel.br/ccs/ enfermagem/acessar.php/page273.html

21 Universidade Estadual de Londrina. PróReitoria de Pesquisa e Pós-Graduação. Evolução programas Stricto sensu [Internet]. 2016. [citado 2018 ago. 25]. Disponível em: http://www.uel.br/proppg/portalnovo/pages/ dados-da-pos.php

22 Guariente MHDM, Kikuchi EM, Carvalho WO, Vannuchi MTO, Dessunti EM, Gastaldi $\mathrm{AB}$, et al. Seivas do currículo integrado de enfermagem. In: Kikuchi E, Guariente MHDM, organizadores. Currículo integrado: a experiência do curso de enfermagem da Universidade Estadual de Londrina. 2a ed. Londrina: EDUEL; 2014.

23 Instituto Brasileiro de Geografia e Estatística. População no último censo de Londrina [Internet]. 2010. [citado 2018 ago. 25]. Disponível em: https://cidades.ibge.gov.br/ brasil/pr/londrina/panorama

24 Universidade Estadual de Londrina. Estude na UEL. Como estudar em uma das melhores instituições de ensino superior do Brasil? [Internet]. 2020 [citado 2020 maio 20]. Disponível em: http://portal.uel.br/estude-nauel/

25 Bardin L. Análise de conteúdo. 4a ed. Lisboa: Edições 70; 2016.

26 Silva MJP. Comunicação tem remédio. 7a ed. São Paulo: Loyola; 2017.

27 Carvalho DPSR, Vitor AF, Cogo ALP, Santos VEP, Ferreira MA Júnior. Teoria da ação comunicativa: subsídio para o desenvolvimento do pensamento crítico. Rev Bras Enferm [Internet]. 2017 nov. [citado 
2018 ago 27]; 70(6):1414-7. Disponível em: http://www.scielo.br/scielo.php?script=sci arttext\&pid=S0034-71672017000601343\&ln $\mathrm{g}=\mathrm{pt \& nrm}=$ iso\&tlng $=\mathrm{pt}$

28 Aguiar AC, Kalil IR, Martínez-Silveira MS, Borges WC, Motta PHFM, Borges GC. O ensino da comunicação na formação profissional em saúde no Brasil: análise da literatura especializada posterior à homologação das diretrizes curriculares nacionais. Cad ABEM [Internet]. 2014 dez. [citado 2018 ago 29]; 10:69-77. Disponível em: http://www. ufrgs.br/pediatria/conteudos-1/seminarios/ subsidios-bibliograficos/documentosbasicos/ Aguiar_O_ensino_da_comunicacao_na_ formacao_profissional_em_saude_no_Brasil_ CadernosABEM_2014.pdf

29 Oliveira AM, Soares E. A comunicação como ferramenta educativa no pré operatório mediato de transplante renal. Rev Pesqui Cuid Fundam (Online) [Internet]. 2018 jul. [citado 2018 ago 26]; 10(3):753-7. Disponível em: http://www. seer.unirio.br/index.php/cuidadofundamental/ article/view/6190/pdf

30 Garcia SD, Vannuchi MTO. O internato de enfermagem da Universidade Estadual de Londrina: conquistas e desafios. Londrina: iNESCO; 2014. 
Souza, A. B. F.; Perales, P. G. P.; Meier, D. A. P. 